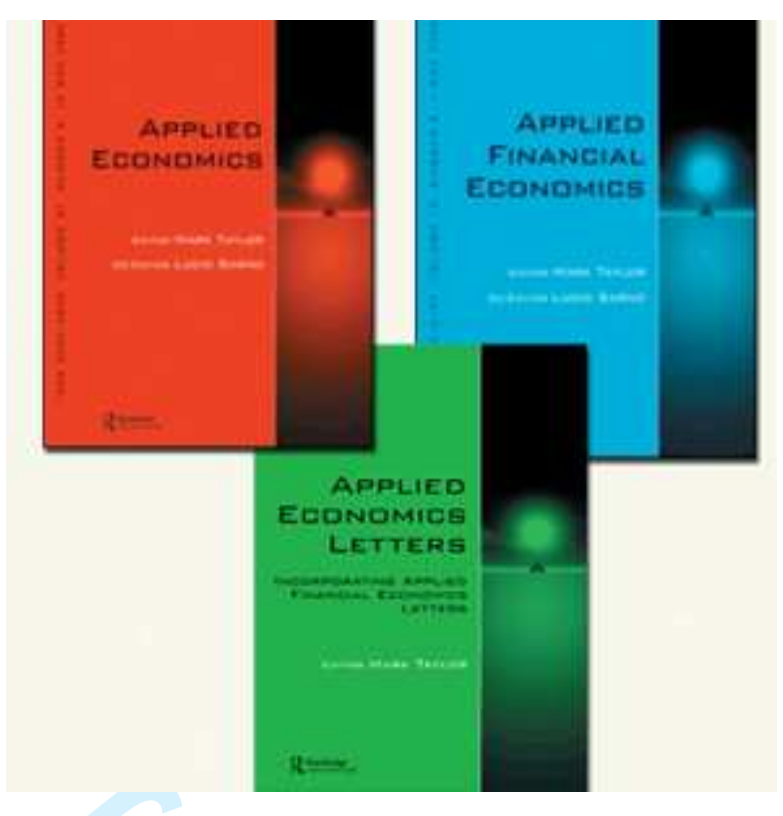

Employment transitions and computer use of older workers

\begin{tabular}{|r|l|}
\hline Journal: & Applied Economics \\
\hline Manuscript ID: & APE-2009-0731.R1 \\
\hline Journal Selection: & Applied Economics \\
\hline Aute Submitted by the & $13-$ Mar-2011 \\
\hline Complete List of Authors: & $\begin{array}{l}\text { Biagi, Federico; Università di Padova, Dipartimento di Scienze } \\
\text { Economiche } \\
\text { Cavapozzi, Danilo; Università di Padova, Dipartimento di Scienze } \\
\text { Economiche } \\
\text { Miniaci, Raffaele; Università di Brescia, Dipartimento di Scienze } \\
\text { Economiche }\end{array}$ \\
\hline JEL Code: & $\begin{array}{l}\text { J14 - Economics of the Elderly < J1 - Demographic Economics < J - } \\
\text { Labor and Demographic Economics, J24 - Human } \\
\text { Capital|Skills|Occupational Choice|Labor Productivity < J2 - Time } \\
\text { Allocation, Work Behavior, and Employment Determination/Creation } \\
<\text { J - Labor and Demographic Economics, J26 - } \\
\text { Retirement|Retirement Policies < J2 - Time Allocation, Work } \\
\text { Behavior, and Employment Determination/Creation < J - Labor and } \\
\text { Demographic Economics }\end{array}$ \\
\hline Keywords: & \begin{tabular}{l} 
Retirement, Skill-biased technological change, Ageing, Labor supply \\
\hline
\end{tabular} \\
\hline
\end{tabular}




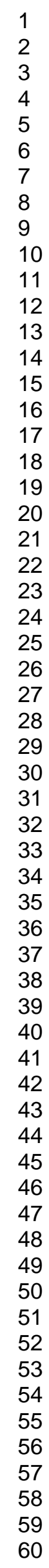

SCHOLARONE ${ }^{m}$
Manuscripts 


\title{
Employment transitions and computer use of older workers
}

\author{
Federico Biagi \\ Università di Padova and S.D.A - Università Bocconi, Milano \\ Danilo Cavapozzi \\ Università di Padova \\ Raffaele Miniaci $^{+}$ \\ Università di Brescia
}

\begin{abstract}
Our empirical analysis studies the impact of computer use on out of employment transitions of older workers, disentangling the effect of using a PC at work from that of being PC literate. Data are drawn from the 2000, 2002 and 2004 waves of the Bank of Italy Survey on Household Income and Wealth. We provide empirical evidence that, even controlling for a wide set of covariates, older employees who use a PC at work have a higher probability of remaining employed in the future. However, our results also indicate that, once PC literacy is controlled for, the use of a PC at work decreases only marginally the risk of becoming not employed (i.e. the effect is smaller than the one registered when we do not control for PC literacy).
\end{abstract}

JEL codes: J26 (Retirement, Retirement Policies), J24 (Human Capital; Skills; Occupational Choice; Labour Productivity), J14 (Economics of the Elderly; Economics of the Handicapped) Keywords: retirement, skill-biased technological change

\footnotetext{
Corresponding author: Raffaele Miniaci, Dipartimento di Scienze Economiche, Università di Brescia, Via San Faustino 74/b, I-25100 Brescia. Tel: +390302988830, Fax: +390302988837. email: miniaci@eco.unibs.it.
} 


\section{Introduction}

After almost twenty years of intense research on skill-biased technological change, it is common wisdom that, considered both singularly and in interaction with other variables defined at the macro, sector and firm level, observed and unobserved skills are among the most important determinants of workers' wages (see Dostie et al., 2010) and employment status. In particular, given the diffusion of ICTs across sectors and professions, older workers with poor "technological endowments" tend to become less and less productive, particularly in industries and professions characterized by rapid technological progress. This leads to lower expected wages and worse expected job conditions, and hence makes (early) retirement more likely. If human capital and technology are complementary, such effect is expected to vary with workers' education. The assessment of the impact of "technological endowments" on early retirement is mainly an empirical issue, in which it is crucial to distinguish between the ability to cope with ICTs and the actual use of ICTs on the job. In fact, ability in dealing with ICTs is a valuable asset by itself, being an indicator of a more general ability to cope with changes affecting job tasks. On the other hand, the use of ICTs on the job might just be an implicit job requirement, which does not necessarily create extra value added, once controlled for job characteristics (for an application to wages see Borland et al., 2004).

This paper studies the impact of ICT knowledge and use on retirement choices, disentangling the effects of technological skills and those due to the use of technology on the job (and hence to implicit job requirements). In our work we focus on out of employment transitions of Italian male employees aged 47-60, using data from the 2000-2004 panel section of the Bank of Italy Survey on Household Income and Wealth (SHIW). Such data allow us to capture the impact of the two variables of interest, considered both separately and together, hence improving upon previous literature, which does not identify the impact of ICT skills separately from the impact of ICT use on the job.

Retirement can be the outcome of a choice between working full time and abandoning the labour market altogether: according to a typical retirement pattern, an individual, once eligible for Social Security benefits, chooses to exit from the labour force. Alternatively, retirement may be a by-product of a firm downsizing, which may include an institutional arrangement that provides older workers with unemployment benefits until they are eligible for Social Security. These workers do not have strong incentives to look for another job and hence they are substantially out of the labour force. Given the characteristics of the Italian labour market, studying older male employees' probability of exiting employment for whatever reason is basically equivalent to studying their retirement probability. 
In our work we first follow previous literature and estimate (what we show is) the combined effect of the ability to use a computer and its actual utilization at work on the probability of transiting out of employment. Then, taking advantage of our dataset, we exploit the information on PC literacy and estimate the impact of having some computer skills on the probability of exiting employment, separately from the additional effect coming from the actual use of a computer on the job.

Our main results show that the combined effect of being computer literate and of using a PC at work is to increase the probability of remaining employed. In all the specifications adopted we consistently find that PC literacy per se and PC use on the job per se have no significant impact on the probability of retirement. However, the two variables considered jointly have an economically and statistically significant effect in reducing the likelihood of retirement. The policy implication is that providing "ICT illiterate" workers with some "ICT knowledge" does not have a positive impact on their employability unless such new skills are actually implemented on the job. This result suggests that the diffusion of ICTs can extend the permanence in the labour market of older workers whenever PC illiterate workers are trained and then put in the position to exploit their new abilities on the job.

Our work proceeds as follows: Section 2 briefly reviews the empirical literature on retirement choices and skill-biased technological change; Section 3 provides prima facie evidence of the relation between computer use and employment based on our SHIW dataset; Section 4 discusses the main results of our analysis; in Section 5 we discuss the potential endogeneity problem affecting our estimates and provide instrumental variables estimates. Section 6 draws the conclusions.

\section{Literature review}

The literature on the determinants of retirement choices is vast (for a review see Lumsdaine and Mitchell, 1999), but only few papers focus on the role of technological skills in the retirement decision. In this case, the econometric analysis is complicated by the fact that the relation between skills and retirement is affected also by the business cycle and by the training policy adopted by firms.

Bartel and Sicherman (1993) study the effect of technological change on the career of older workers. They show that, everything else constant, individuals retire later in industries in which technological change is particularly rapid. Further, an unexpected rise in the depreciation rate of human capital, for instance following an unexpected rise in the rate of technological change, leads to earlier retirement. 
Friedberg (2003) investigates whether there exists evidence of a significant relationship between computer use and retirement. In her analysis the basic insight is that computers have affected the demand for labour in various ways. First, they tend to be a substitute for unskilled labour and routine tasks. Second, they have altered the performance of non-routine tasks, mainly held by skilled workers. Finally, computerization alters the "bundle of skills and tasks that define a job". These changes can affect the retirement choice of older individuals, given that older generations tend to be less educated and hence more likely to be assigned to routine jobs. For these workers training may be generally less profitable given the higher investment costs and the reduced time horizon over which they can be recouped. Friedberg uses the US Health and Retirement Study (from 1992 to 1996) to study how the frequency of computer use at work affects the transitions towards retirement of workers aged 50-62 in 1992. She takes into account the possible correlation between the use of the computer and the unobserved propensity to retire later by estimating a linear probability model using an instrumental variables (IV) approach. In particular, she opts to instrument PC utilization by older workers with the percentage of computer users among prime-age workers in the same occupation and industry. Her findings show that, in the long run case (i.e. over a four-year horizon), even controlling for many individual, firm and sector characteristics, computer use tends to induce delayed retirement. In a very similar framework Schleife (2006) uses the German Socio Economic Panel to investigate the effect of computer use at work on the retirement outcomes of employed males aged 50-60 in 1997. As Friedberg (2003), she models retirement by means of a linear probability model, distinguishing between different timing of retirement (transitions occurring within 1999 and those occurring within 2001 are studied separately). The potential endogeneity of computer use on the job is addressed by means of an instrumental variables approach that considers computer use at home as the additional instrument. Her IV results provide no evidence that Germans who use a computer at work tend to postpone their retirement.

\section{The data}

Our data are drawn from the Bank of Italy Survey of Household Income and Wealth (SHIW), which, every two years, provides a sample of about 8,000 households, representative of the Italian population. It contains detailed information on the socioeconomic conditions of respondents at the individual and household level ${ }^{1}$. The 2000 wave of SHIW provides us with information on the ability of individuals in the use of computers and, for those who are working, on their use of a PC at work. Specifically, each household member is asked to self-assess her/his ability in using personal computers according to an increasing five-step scale spanning from "none" to "very good". Since

\footnotetext{
${ }^{1}$ See Banca d'Italia (2002) for further details.
} 
half of the households participating to the survey are repeatedly interviewed, our analysis exploits the panel section coming from the 2000, 2002 and 2004 waves $^{2}$.

Following Friedberg (2003) and Schleife (2006), we distinguish between transitions out of employment occurring within the period 2000-2002 and transitions within the period 2000-2004. Short run transitions are studied on the basis of a sample of 512 male employees aged 47-60 in year 2000 and tracked down until 2002, while the analysis of long run transitions is carried out by considering only the 362 workers who remain in the survey until 2004. Thus, the sample selection adopted to analyze long run transitions does not impose any condition on the employment status in 2002 and the reduction in the number of observations is mainly due to the rotating design of the panel survey.

Table 1 presents the distribution of the PC literacy self-assessment by educational attainment in our two samples. Overall, when looking at the sample used to analyze transitions out of employment in the short run (2000-2002 sample), more than one half (55 percent) of the workers are not able to use a PC, 28 percent of them self-classify their skills as modest or fair and only 17 percent rate their skills as good or very good. However, this pattern is strongly affected by individual educational attainments and, in line with the existing literature; we find a strong positive correlation between education and the level of PC literacy. In fact, when we split the sample in two groups (in the former we gather employees who have at most a vocational secondary school degree: i.e. low-education; in the latter we have workers with at least an upper secondary school degree: i.e. high-education) we find that 79 percent of the employees with low education have no PC skills, but this percentage falls to 24 percent in the high-education group. The fraction of respondents with (at least) good PC skills is 4 percent among low-education workers, but such percentage increases to 34 percent when we look at high-education employees. Similar considerations hold for the sample used to analyze long-run transitions (2000-2004 sample).

\section{***** TABLE 1 ABOUT HERE *****}

In the remaining part of our work, we rearrange the original scale of PC literacy selfassessments and define a dichotomous variable that takes value 1 if the individual declares to have at least modest ability in PC utilization (45 percent of cases) and 0 otherwise. While this reduces the sample variability of PC literacy, it also has the effect of reducing the measurement error due to the fact that individuals self-evaluate their skills ${ }^{3}$.

\footnotetext{
${ }^{2}$ The longitudinal section of SHIW is a rotating panel.

${ }^{3}$ Individuals with the same actual level of PC skills may provide different self-assessments of their knowledge due to
} 
Analogously, the diffusion of PC utilization at work is positively correlated with education levels. As displayed in Table 2, although only 34 percent of employees in the 2000-2002 sample use a personal computer on the job, this percentage rises to 65 percent when we consider high-education individuals and drops to 11 percent for the low-education group. Blue-collar workers are by far less likely to use a PC on the job than white-collars. It should also be noted that the fraction of PC users at work increases to 77 percent among employees with PC literacy.

As previously explained, in our analysis transitions out of employment for whatever reason are considered equivalent to retirement. This choice is motivated on the ground that we are looking at older workers (individuals aged 49 or more in year 2000), that Italy has many institutional arrangements that are substantially equivalent to early retirement (according to which inactive workers are still formally in the labour force) and that our ultimate goal is to test whether ICT knowledge and its use exert some effect on the likelihood of remaining active in the labour market. Table 3 reports that in the 2000-2002 sample 19 percent of employees no longer work at the end of the period. This fraction increases when we extend the time-horizon over which transitions can occur. In fact, 30 percent of employees at work in 2000 exit from employment by 2004. As expected, the likelihood of becoming not employed increases with age: only 6 percent of employees aged 47-49 in 2000 are not at work in 2002, but this percentage more than doubles if we consider the age range 50-52 and steadily rises for older individuals. Furthermore, employees with low education exhibit transition rates twice those of high-education employees.

\section{$* * * * *$ TABLE 3 ABOUT HERE $* * * * *$ \\ $* * * * *$ TABLE 4 ABOUT HERE $* * * * *$}

In Table 4 we look at the employment status of individuals transiting out of employment in our sample. In both time-horizons the exit towards labour retirement is by far the most common. Of those transiting out of employment in 2000-2002, 69 percent become job pensioners, while 28 become unemployed. However, when we look at the 2000-2004 transitions we find that 87 percent become pensioners and only 11 percent end up unemployed.

different reporting styles. 
Notice that in the subsample of those who are employed in 2000, quit employment by 2002 and participate to the survey in 2004, only 8 percent are back to work by 2004 . That is, transiting out of and back to employment involves about 1.5 percent $\left(0.19^{*} 0.08\right)$ of the employees in the sample. These raw figures make us confident that -for this age group-transitions out of employment tend to be permanent, hence confirming that ours is an appropriate way of modelling the retirement process of the older workers in our sample.

Table 5 provides descriptive evidence about how transition rates vary with PC literacy and PC utilization at work. In the short run, 10 percent of employees with PC literacy transit out of employment. This percentage more than doubles among workers with no ICT skills. Analogously, we estimate the probability of quitting employment by 2002 for non PC users to be 25 percent, which drops to 9 percent for users.

\section{TABLE 5 ABOUT HERE *****}

If we disaggregate the transition rate of workers with some PC skills by the variable that captures the use of a PC on the job, we find that the fraction of employees quitting employment is 17 percent if they do not use a PC at work and it drops to a mere 9 percent among users. Therefore, the difference between the exit rates from employment of users and non users ( 9 vs 25 percent) is reduced by one third ( 9 vs 17 percent) when we consider PC literate individuals only. In the 20002004 horizon, the variation in the transition rates between PC users and not PC users (at work) amounts to about 17 percentage points. If we focus on PC literate employees, this difference remains unchanged in absolute values but it is no longer statistically significant at the 5 percent level. Finally, it should be noticed that, among employees who do not use a PC on the job, being PC literate is not associated with any significant variation in the probability of quitting employment. This latter result is found for both the short and the long run.

These raw figures suggest that the transition rates differential associated with PC use at work found in the overall sample shrinks if we consider PC literate individuals only. The empirical specifications in the next section will seek to assess whether this evidence is confirmed once we control for individual and household characteristics in a multivariate framework.

\section{Multivariate analysis}

In our estimation exercise we first follow the existing literature and analyze the combined effect of being computer literate and using a PC at work on the probability of transiting out of 
where PC_skill equals one if the individual has some control on computer technology, and zero otherwise, and $P C_{-}$work is equal to one if he uses a computer at work. As it is not possible to use a $\mathrm{PC}$ at work without being PC literate (that is, it is not possible to have $P C \_s k i l l=0$ and $P C \_$work $=1$ at the same time), then $P C_{-}$skill $\times P C_{-}$work $=P C_{-}$work. This amounts to saying that $\gamma$, often interpreted as the coefficient on the variable $P C_{-}$work alone, in fact measures the combined effect of being PC literate and using a PC at work.

As we have information on individual PC literacy, we can enrich specification (1) and try to disentangle the effect of PC skills from that of PC utilization:

$$
E\left[y_{i} \mid \mathbf{x}_{i} ; \boldsymbol{\beta}\right]=\operatorname{Pr}\left(y_{i}=1 \mid \mathbf{x}_{i} ; \boldsymbol{\beta}\right)=\mathbf{x}_{i}^{\prime} \boldsymbol{\beta}+\gamma_{0} P C_{-} \text {skill }_{i}+\gamma_{1} P C_{-} \text {skill }_{i} \times P C_{-} \text {work }_{i}
$$

In equation (2), $\gamma_{0}$ identifies the effect of being PC literate for the employees who do not use a PC at work, while $\gamma_{1}$ measures the impact of using a PC at work for PC literate workers. As a result, $\gamma_{0}+\gamma_{1}$ is the combined effect on transition probability of PC skills and PC use on the job.

In all specifications, the vector $\mathbf{x}_{i}$ includes the number of household components, age, number of years of contribution to Social Security (a proxy for pension wealth), number of days spent at home for illness (a proxy for health status), education, region of residence and home tenure. Moreover, we control for job characteristics, sector of employment and firm dimension in order to allow for heterogeneity in the rate of diffusion of new technologies in the economy. Regardless of the time horizon considered, the control factors included in our specifications refer to year 2000 . Table A.1 in the Appendix lists all the explanatory variables used in our empirical analysis along with their sample averages ${ }^{4}$. Tables A.2 and A.3 report the full results of our estimation exercise of,

\footnotetext{
${ }^{4}$ Our results are confirmed even conditioning on an alternative set of control factors including labour income and other household income. This set of results is available upon request.
} 
respectively, equation (1) and equation (2), while Table 6 reports the OLS estimates of our main parameters of interests in the two-year (2000-2002) and in the four-year period (2000-2004).

\section{$* * * * *$ TABLE 6 ABOUT HERE $* * * * *$}

The effects of the control variables in $\mathbf{x}$ present the expected sign. In particular, they confirm that the likelihood of retirement increases with age and with cumulated pension wealth. Moreover, public sector employees tend to retire later.

Considering equation (1), the results for the two-year period confirm the descriptive evidence of Table 5: male workers who use a computer at work retire significantly later. In particular, the retirement probability is reduced by about 12 percentage points. If we look at Table 5 , we notice that the raw difference in transition rates between PC users and not PC users at work amounts to 16 percentage points. This means that controlling for individual and household characteristics reduces the raw variation in the sample by one fourth. Similar considerations hold for the four-year interval.

When we focus on equation (2)- that is, when we include the dummy variable for PC literacyour estimates still confirm the prima facie evidence of Table 5: in the longer period the effect of being PC literate but not using a PC on the job is negligible $\left(\hat{\gamma}_{0}=-0.002\right)$, while, in the two-year horizon, PC literacy and PC use at work have almost the same relevance $\left(\hat{\gamma}_{0}=-0.08, \hat{\gamma}_{1}=-0.06\right)$. In both cases only the estimate of the combined two effects $\left(\hat{\gamma}_{0}+\hat{\gamma}_{1}\right)$ is statistically different from zero at $\alpha=5 \%$ and its size is (as expected) similar to the estimate of the parameter $\gamma$ showing up in equation (1).

\section{Robustness check: instrumental variables estimates}

The OLS estimates discussed so far can be affected by the potential endogeneity of PC skills and PC utilization at work with respect to employment status. Endogeneity of PC skills may arise because individuals able to use a computer possess unobserved characteristics (such as higher levels of human capital not captured by education) that make them more likely to maintain a job in the future. In addition, individuals who plan to retire later might also decide to improve their computer skills in order to be more valuable within the firm and, in general, in the labour market. Finally, older workers who decide to invest in PC skills may expect a longer period of permanence in the labour market, in which the benefits from their training can be fully recouped. As for the use of a PC at work, this is related to the endowment of PC skills: in our sample, about 80 percent of the individuals with PC literacy actually use a personal computer at the workplace. Hence, all the 
concerns for the potential endogeneity of PC skills apply to PC utilization at work as well. Further, if firms decide to devote financial resources to ICT training for older workers, they may select only those workers expected to retire later, providing them with incentives to prolong their working relationship in order to ensure the financial profitability of this investment for both parties.

If the exogeneity assumption of the explanatory variables in equations (1) or (2) fails, standard OLS techniques produce biased estimates of the causal effect of interest. Aware of this, we also estimate the linear probability model specification by means of the two-stage least-squares (2SLS) approach. The set of additional instruments we use in order to achieve the identification of the parameters of interest consists of the number of other family members with some computer skills, its interactions with the number of household components and the qualification of the employee (blue/white collar) and, finally, the number of children in the household.

The use of the number of family members with PC skills is motivated by the empirical evidence reported in Miniaci and Parisi (2006), who show that within-household peer effects are indeed relevant for the diffusion of computer skills: according to the 2000 SHIW wave, $70 \%$ of individuals co-habitating with somebody skilled are skilled, and this percentage falls to less than $10 \%$ if nobody else in the family is able to use a computer. The interaction with the number of household members allows this relationship to vary with household size, while the interaction with the professional qualification reflects the conjoint role played by family and workplace characteristics in determining individual propensity towards computer use. Finally, the inclusion of the number of children in the household among the additional instruments is motivated by the fact that living with children increases the probability that parents are PC literate and use a PC on the job.

The consistency of the 2SLS estimator is guaranteed if the additional set of instruments is correlated with the explanatory variables suspected to be endogenous and unrelated with the dependent variable. In our case, this amounts to say that the additional instruments may affect employees skills and computer utilization (relevant instruments) but, once conditioned on the control factors in the vector $\mathbf{x}_{i}$, they do not affect their employment choices (exogenous instruments). We carry out formal statistical tests to check whether our instruments fulfil these requirements. Our crucial identification assumption is that computer skills of family members do not affect the household formation process, once controlled for other relevant observable characteristics. Thus, we do not deny that assortative matching might be at work, but we assume that once controlled for age, professional qualification, education and area of residence, the process of household formation and dissolution is not affected by computer skills of family members (see Miniaci and Parisi 2006 for further discussion of the issue). 


\section{***** TABLE 7 ABOUT HERE *****}

The 2SLS estimates of the main parameters of interests are reported in Table 7 (full results can be found in Tables A.1). For what concerns equation (1), these results confirm the evidence based on OLS (see Table 6), the main difference being the larger standard errors characterizing the instrumental variable estimator. When we add the PC literacy dummy to the specification, the differences between the 2SLS and OLS point estimates become noteworthy, as the overall effect $\gamma_{0}+\gamma_{1}$ is halved and the estimated $\gamma_{1}$ is positive. However, due to the efficiency loss, neither the single nor the combined effects are statistically different from zero.

We test for the joint insignificance of the additional instruments in the first stage equations and always reject the null hypothesis (see the results of the $F$-test in Table A.2). Further, the Hansen $J$ statistics always accept the null of validity of the exclusion restrictions. These specification tests show that the additional instruments used are, respectively, relevant and exogenous and that the resulting 2SLS estimates are consistent. However, the Hausman test never rejects the null hypothesis of exogeneity of the explanatory variables included in our specifications (1) and (2). This evidence suggests that the endogeneity of PC skills and PC utilization at work is not a major concern in our case and we can rely upon OLS estimates of our parameters of interests.

\section{Conclusions}

The Bank of Italy Survey on Household Income and Wealth provides information both on the ability in the use of a computer for all respondents and on its use on the job for those who are at work. We exploit this unique characteristic to disentangle the effect of being PC literate from that of using a PC at work on the probability of transiting out of employment for the cohort of Italian male employees aged 47-60 in year 2000 .

Our main findings show that the combined effect of being skilled and using a PC at work is to reduce the probability of exiting employment by 12 percentage points, both in the 2-year and 4-year horizon. Given that the average transition rates in our samples are 19 and 30 percent, respectively, for the 2000-2002 and for the 2000-2004 interval, the estimated combined effect is quite sizable. According to the statistics provided by the main Social Security funds for Italian private and public sector workers (INPS and INPDAP), we can estimate that, if all employees had used a PC on the job, the number of new pension benefits withdrawn between 2001 and 2004 would have decreased 


\begin{abstract}
Acknowledgments: The paper previously circulated as "Technology, Skills and Retirement", Marco Fanno Working Paper, University of Padua. The authors gratefully acknowledge the financial support from the MIUR, the University of Padova and the EU-grants COMPARE (research contract no. CIT5-028857) and SHARELIFE (research contract no. CIT4-028812). We wish to thank the editor, an anonymous referee, Lorenzo Cappellari and the participants at the SIEP Conference (2006), the ECINEQ Meeting (2007), the EALE Conference (2007) and at the seminars given at the Universities of Padua, Milan (Università Cattolica del Sacro Cuore and University of Milano-Bicocca) and at the University of Balearic Islands (Palma de Mallorca). The Bank of Italy Survey on Household Income and Wealth used in this paper is publicly available at www.bancaditalia.it.
\end{abstract}

\footnotetext{
${ }^{5}$ Data are downloadable from the websites www.inps.it and www.inpdap.it.
} 


\section{References}

Banca d'Italia (2002), "Italian Household Budgets in 2000", Supplements to the Statistical Bulletin, XII, 6, Rome: Banca d'Italia.

Bartel, A. and Sicherman, N, (1993), "Technological Change and Retirement Decisions of Older Workers", Journal of Labor Economics, 11(1), 162-83.

Borland, J., Hirschberg J. and Lye J. (2004), Computer knowledge and earnings: evidence for Australia, Applied Economics, 36, (17) 1979-1993

Dostie, B., Jayaraman, R. and Trèpanier, M. (2010), "What (if any) Are the Returns to Computer Use?", Applied Economics, 42 (30), 3903-3912.

Friedberg, L. (2003), "The Impact of Technological Change on Older Workers: Evidence from Data on Computer Use", Industrial and Labor Relations Review, 56 (3), 511-529.

Lumsdaine R and Mitchell, O. (1999), "New Developments in the Economics of Retirement", in O. Ashenfelter and D. Card eds., Handbook of Labor Economics, Vol. III, North-Holland, Amsterdam, 3261-3308.

Miniaci R. and M. L. Parisi (2006), "Social Interactions and the Digital Divide: Identification and Policy Implication”, Contributions to Economic Analysis \& Policy, 5(1), article 29.

Schleife, K. (2006), "Computer Use and Employment Status of Older Workers. An Analysis Based on Individual Data”, Labour, 20 (2) 325-348. 
Table 1: Self assessed PC literacy by education (percentage points).

\begin{tabular}{cccc}
\hline$\%$ & $\begin{array}{c}\text { Low education } \\
\text { (at most vocational }\end{array}$ & $\begin{array}{c}\text { High education } \\
\text { (at least upper }\end{array}$ & All \\
secondary school degree) & secondary school degree) & \\
\hline
\end{tabular}

2000-2002

$\begin{array}{lccc}\text { Absent } & 78.77 & 24.09 & 55.27 \\ \text { Modest } & 11.64 & 17.73 & 14.26 \\ \text { Fair } & 5.14 & 24.55 & 13.48 \\ \text { Good } & 3.77 & 22.73 & 11.91 \\ \text { Very good } & 0.68 & 10.91 & 5.08\end{array}$

2000-2004

\begin{tabular}{lccc} 
Absent & 76.81 & 22.58 & 53.59 \\
Modest & 13.04 & 16.13 & 14.36 \\
Fair & 5.31 & 23.23 & 12.98 \\
Good & 3.86 & 24.52 & 12.71 \\
Very good & 0.97 & 13.55 & 6.35 \\
\hline
\end{tabular}

Table 2: Percentage of PC users at work by education, job characteristics and PC literacy.

\begin{tabular}{lcc}
\hline$\%$ & $\mathbf{2 0 0 0 - 2 0 0 2}$ & $\mathbf{2 0 0 0 - 2 0 0 4}$ \\
\hline High education & 64.55 & 67.10 \\
Low education & 11.30 & 12.56 \\
& & \\
Blue-collars & 6.82 & 7.50 \\
White-collars & 54.79 & 58.42 \\
PC literate & 76.42 & 77.38 \\
All & 34.18 & 35.91 \\
\hline \multicolumn{2}{l}{ Note: By definition, those who are not PC literate do not use a PC at work. }
\end{tabular}

Table 3: Transition rate by age, education and region of residence (percentage points).

\begin{tabular}{lcc}
\hline$\%$ & $\mathbf{2 0 0 0 - 2 0 0 2}$ & $\mathbf{2 0 0 0 - 2 0 0 4}$ \\
\hline Age 47-49 & 5.80 & \\
Age 50-52 & 15.29 & 9.18 \\
Age 53-55 & 26.45 & 26.23 \\
Age 56-60 & 38.55 & 47.56 \\
& & 50.00 \\
High education & 10.45 & 17.42 \\
Low education & 25.68 & 40.10 \\
All & 19.14 & 30.39 \\
\hline
\end{tabular}


Table 4: Employment status of workers transiting out of employment (percentage points).

\begin{tabular}{lcc}
\hline$\%$ & $\mathbf{2 0 0 0 - 2 0 0 2}$ & $\mathbf{2 0 0 0 - 2 0 0 4}$ \\
\hline Unemployed & & \\
Job pensioner & 27.55 & 10.91 \\
Non-job pensioner & 69.39 & 87.27 \\
\hline \multicolumn{2}{c}{ Note: Non-job pensioner category includes disability, social and survivor pensions. }
\end{tabular}

Table 5: Probability of transiting out of employment by PC literacy and PC use at work.

\begin{tabular}{lccc|ccc}
\hline$\%$ & \multicolumn{3}{c|}{$\mathbf{2 0 0 0 - 2 0 0 2}$} & \multicolumn{3}{c}{$\mathbf{2 0 0 0 - 2 0 0 4}$} \\
\hline & $\begin{array}{c}\text { Not PC-user } \\
\text { at work }\end{array}$ & $\begin{array}{c}\text { PC-user } \\
\text { at work }\end{array}$ & All & $\begin{array}{c}\text { Not PC- } \\
\text { user at } \\
\text { work }\end{array}$ & $\begin{array}{c}\text { PC-user at } \\
\text { work }\end{array}$ & All \\
\hline Not PC-literate & 26.15 & & 26.15 & 37.11 & & 37.11 \\
& $(2.62)$ & & $(2.62)$ & $(3.48)$ & & $(3.48)$ \\
PC-literate & 16.67 & 8.57 & 10.48 & 34.21 & 19.23 & 22.62 \\
& $(5.12)$ & $(2.12)$ & $(2.03)$ & $(7.80)$ & $(3.47)$ & $(3.24)$ \\
All & 24.63 & 8.57 & 19.14 & 36.64 & 19.23 & 30.39 \\
& $(2.35)$ & $(2.12)$ & $(1.74)$ & $(3.17)$ & $(3.47)$ & $(2.42)$ \\
\hline
\end{tabular}

Note: Standard errors are in parentheses.

Table 6: Linear probability model, effects of PC literacy and PC use at work on the probability of transiting out of employment. OLS estimates

\begin{tabular}{cc|ccc}
\hline & $\begin{array}{c}\text { Equation (1) } \\
\text { Combined effect of } \\
\text { PC literacy and PC } \\
\text { use at work }(\gamma)\end{array}$ & $\begin{array}{c}\text { PC literacy } \\
\left(\gamma_{0}\right)\end{array}$ & $\begin{array}{c}\text { PC use at } \\
\text { work }\left(\gamma_{1}\right)\end{array}$ & $\begin{array}{c}\text { Combined effect of } \\
\text { PC literacy and PC } \\
\text { use at work }\left(\gamma_{0}+\gamma_{1}\right)\end{array}$ \\
\hline $2000-2002: n=512$ & $-0.116^{* * *}$ & -0.079 & -0.058 & $-0.137^{* * *}$ \\
& $(0.038)$ & $(0.050)$ & $(0.050)$ & $(0.041)$ \\
\hline $2000-2004: n=362$ & $-0.117^{* *}$ & -0.002 & $-0.115^{*}$ & $-0.118^{* *}$ \\
& $(0.048)$ & $(0.072)$ & $(0.070)$ & $(0.053)$ \\
\hline
\end{tabular}

Note: Standard errors in parentheses. Inference is robust to arbitrary heteroskedasticity. ${ }^{* * *}$ : p-value $\leq 0.01,{ }^{* *}: 0.01<\mathrm{p}$ value $\leq 0.05, *: 0.05<$ p-value $\leq 0.1$. 
Table 7: Linear probability model, effects of PC literacy and PC use at work on the probability of transiting out of employment. IV estimates

\begin{tabular}{cc|ccc}
\hline & Equation (1) & \multicolumn{3}{c}{ Equation (2) } \\
\hline & $\begin{array}{c}\text { Combined effect of } \\
\text { PC literacy and PC } \\
\text { use at work }(\gamma)\end{array}$ & $\begin{array}{c}\text { PC literacy } \\
\left(\gamma_{0}\right)\end{array}$ & $\begin{array}{c}\text { PC use at } \\
\text { work }\left(\gamma_{1}\right)\end{array}$ & $\begin{array}{c}\text { Combined effect of } \\
\text { PC literacy and PC } \\
\text { use at work }\left(\gamma_{0}+\gamma_{1}\right)\end{array}$ \\
\hline $2000-2002: n=512$ & -0.120 & -0.109 & 0.022 & -0.087 \\
& $(0.084)$ & $(0.224)$ & $(0.308)$ & $(0.111)$ \\
\hline $2000-2004: n=362$ & -0.124 & -0.196 & 0.129 & -0.067 \\
& $(0.109)$ & $(0.259)$ & $(0.358)$ & $(0.137)$ \\
\hline
\end{tabular}

Note: Standard errors in parentheses. Inference is robust to arbitrary heteroskedasticity. $* * *$ : p-value $\leq 0.01, * *: 0.01<\mathrm{p}$ value $\leq 0.05, *: 0.05<$ p-value $\leq 0.1$. 


\section{Appendix}

Table A.1: Summary statistics of the explanatory variables, OLS and 2SLS estimates of the linear probability model for transitions out of employment. 2000-2002

\section{0-2004}

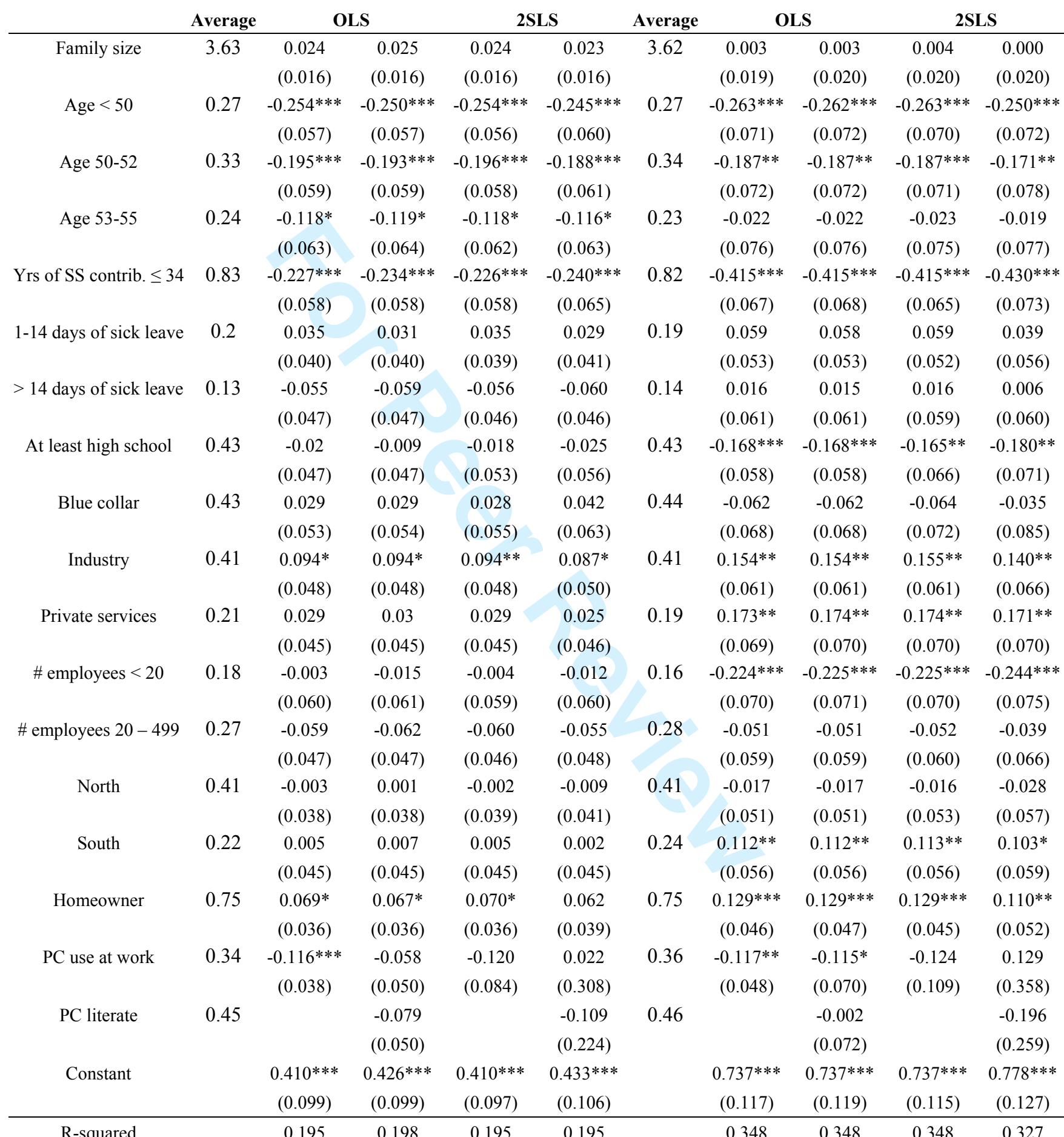

Observations $\quad 512 \quad 362$ 
Table A.2: 2SLS specification tests

\begin{tabular}{|c|c|c|c|c|}
\hline & \multicolumn{2}{|r|}{$2000-2002$} & \multicolumn{2}{|c|}{$2000-2004$} \\
\hline & \multicolumn{4}{|c|}{ Test for the relevance of the instruments $\left(\chi_{4}^{2}\right)$} \\
\hline$F$-test (PC use at work) & \multicolumn{2}{|r|}{29.896} & \multicolumn{2}{|r|}{26.496} \\
\hline p-value & \multicolumn{2}{|r|}{0.000} & \multicolumn{2}{|r|}{0.000} \\
\hline$F$-test (PC literacy) & \multicolumn{2}{|r|}{64.356} & \multicolumn{2}{|r|}{57.363} \\
\hline \multirow[t]{3}{*}{ p-value } & \multicolumn{2}{|r|}{0.000} & \multicolumn{2}{|r|}{0.000} \\
\hline & \multicolumn{4}{|c|}{ Overidentification tests } \\
\hline & $\begin{array}{c}\text { PC use at } \\
\text { work }\left(\chi_{3}^{2}\right)\end{array}$ & $\begin{array}{c}\text { PC use at work and PC } \\
\text { literacy }\left(\chi_{2}^{2}\right)\end{array}$ & $\begin{array}{l}\text { PC use at work } \\
\left(\chi_{3}^{2}\right)\end{array}$ & $\begin{array}{c}\text { PC use at work and PC } \\
\text { literacy }\left(\chi_{2}^{2}\right)\end{array}$ \\
\hline Hansen $J$-test & 0.552 & 0.340 & 0.878 & 0.388 \\
\hline \multirow[t]{3}{*}{$\mathrm{p}$-value } & 0.907 & 0.844 & 0.831 & 0.824 \\
\hline & \multicolumn{4}{|c|}{ Exogeneity tests } \\
\hline & $\begin{array}{l}\text { PC use at } \\
\text { work }\left(\chi_{1}^{2}\right)\end{array}$ & $\begin{array}{c}\mathrm{PC} \text { use at work and PC } \\
\text { literacy }\left(\chi_{2}^{2}\right)\end{array}$ & $\begin{array}{l}\text { PC use at work } \\
\left(\chi_{1}^{2}\right)\end{array}$ & $\begin{array}{c}\text { PC use at work and PC } \\
\text { literacy }\left(\chi_{2}^{2}\right)\end{array}$ \\
\hline Hausman exogeneity test & 0.004 & 0.174 & 0.005 & 0.345 \\
\hline p-value & 0.950 & 0.840 & 0.944 & 0.708 \\
\hline
\end{tabular}

